invoked, only one of which is spatiotemporal. Biogeographers trace the spatiotemporal boundaries of species, discovering for example that catalpa trees are indigenous to the Wabash Valley. The other sorts of boundaries are conceptual and concern definitions. All triangles, and only triangles, have three sides.

Although not all species reproduce sexually, those that do so produce a genealogical nexus, and species are chunks of it. At best, the way that characteristics are distributed is secondary to descent. In referring to species as the groupings that evolve by variation and selection, I do not mean to imply that this is the only way of defining species. Lots of people do it in lots of different ways, but Fernández-Armesto and Dunbar both introduce Darwin and evolution. So they need to be made aware of one quite prevalent way of construing species, including humans, especially as it provides rather a different perspective on the human species. FernándezArmesto devotes his final chapter to issues surrounding morality. Once again, as he sees it, the issue is characteristics. Which characteristics are relevant to morality, and which organisms exhibit them? What should we do with non-human organisms that have the characteristics that we use to confer moral rights?

From the evolutionary perspective, how- ever, the issue is genealogy, not distributions of characteristics. Even though some pigs may seem brighter than some people, pigs do not belong to the same chunk of the genealogical nexus as people. Evolutionary theory is inherently species-ist. If we discovered that dolphins have sufficiently welldeveloped language skills that we could strike up conversations with them, they would still be dolphins and we would still be humans. Social and moral problems would arise, but as biological species we would remain unique and distinct.

David L. Hull is emeritus professor at the Department of Philosophy, Northwestern University, Evanston, Illinois 60208-1315, USA.

\title{
Walking on their ribs
}

\section{Geoffroy Saint-Hilaire: A Visionary Naturalist \\ by Hervé Le Guyader, \\ transl. Marjorie Grene \\ University of Chicago Press: 2004. 302 pp.

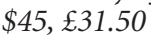

\section{Nick Hopwood}

In evolutionary terms, the most remarkable discoveries of developmental biology in the 1980s and 1990s were that the molecular mechanisms of anteroposterior axis formation are shared across most of the animal kingdom, and that vertebrates form a dorsoventral axis in a similar way to insects, only upside-down. This axial inversion had a special appeal because it seemed to confirm an old and much-derided view. Its first proponent was the French zoologist Étienne Geoffroy Saint-Hilaire, subject of this book by Hervé Le Guyader.

In 1830, Geoffroy faced his one-time friend and long-term colleague Georges Cuvier at the Muséum d'Histoire Naturelle in Paris, in one of the most famous controversies in the history of science. Cuvier, the most powerful comparative anatomist of the age, had divided the animal kingdom into four completely separate branches: vertebrates, articulates (largely arthropods and annelids), molluscs and radiates (echinoderms, cnidarians and various other groups). Even within these divisions, he allowed structural similarity to result solely from the same functional demands.

Geoffroy, by contrast, taught that function did not really matter, nor even form; what counted were the connections between the parts. He founded a 'philosophical' anatomy on 'analogy' (homology, to us), and pushed the idea that all animals are built to a single plan. Having established a common scheme for vertebrates, in 1820 he extended it to the articulates. Insects, he pronounced,

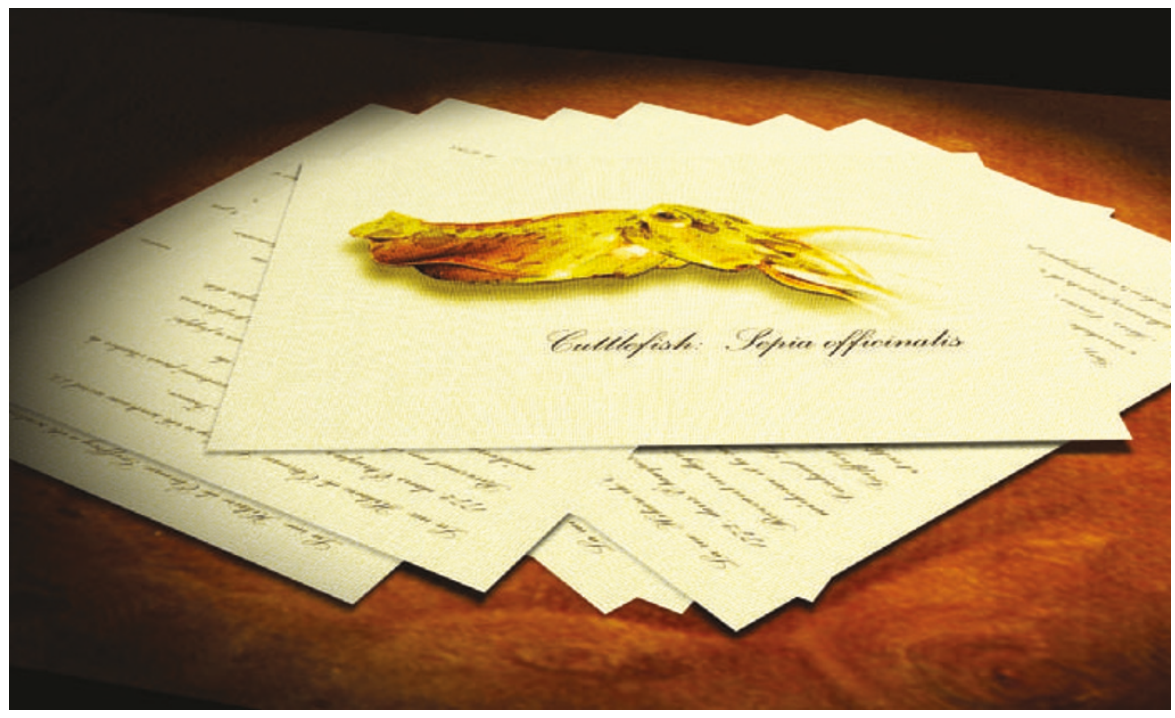

are vertebrates that live within their vertebral columns and walk on their ribs.

Cuvier restrained himself until a decade later, when Geoffroy exploited two young naturalists' suggestion that cuttlefish, representing molluscs, were like vertebrates doubled back on themselves. The simmering dispute now boiled over into a confrontation on the floor of the Academy of Sciences in Paris that captivated the learned world and newspaper-reading public alike.

As Toby Appel showed in The CuvierGeoffroy Debate (Oxford University Press, 1987), much more than cephalopod anatomy was at stake. Cuvier's functionalism opposed Geoffroy's morphology. The austere, logical Protestant fought the intuitive, impetuous, romantic Deist. Cuvier's factdriven, establishment science was pitted against Geoffroy's broad speculation and alliances with progressive forces beyond the academy. Cuvier is usually said to have won, and on the narrow issue he did, but Geoffroy's philosophical anatomy was more influential than used to be thought. For leading naturalists in the next generations, both positions seemed too extreme. In finding a resolution, homology was made into evidence of darwinian evolution - and some darwinists argued that the vertebrates originated from annelids by inversion of the dorsoventral axis.

Le Guyader's book, first published in French six years ago, offers a judicious selection of Geoffroy's works, each with a short introduction. These texts have never been translated before because nineteenth-century British naturalists read them in French, and because by the middle of the century Geoffroy had been marginalized. We have the preliminary discourses to both volumes of his Anatomical Philosophy; the first of three treatises on the organization of insects, which deals with the anteroposterior axes of insects and vertebrates; the recently muchcited review, "General considerations on the vertebra", with its reflections on dorsoventral organization and the figure of the insideout and upside-down lobster; and the whole of the Principles of Zoological Philosophy, Geoffroy's record of the 1830 debate.

Anglophone biologists and historians of science will be glad to have these scarce and important works so readily available. Some additional editorial work might, though, have produced more scholarly and userfriendly texts. Martin Rudwick's translations in Georges Cuvier, Fossil Bones and Geological 


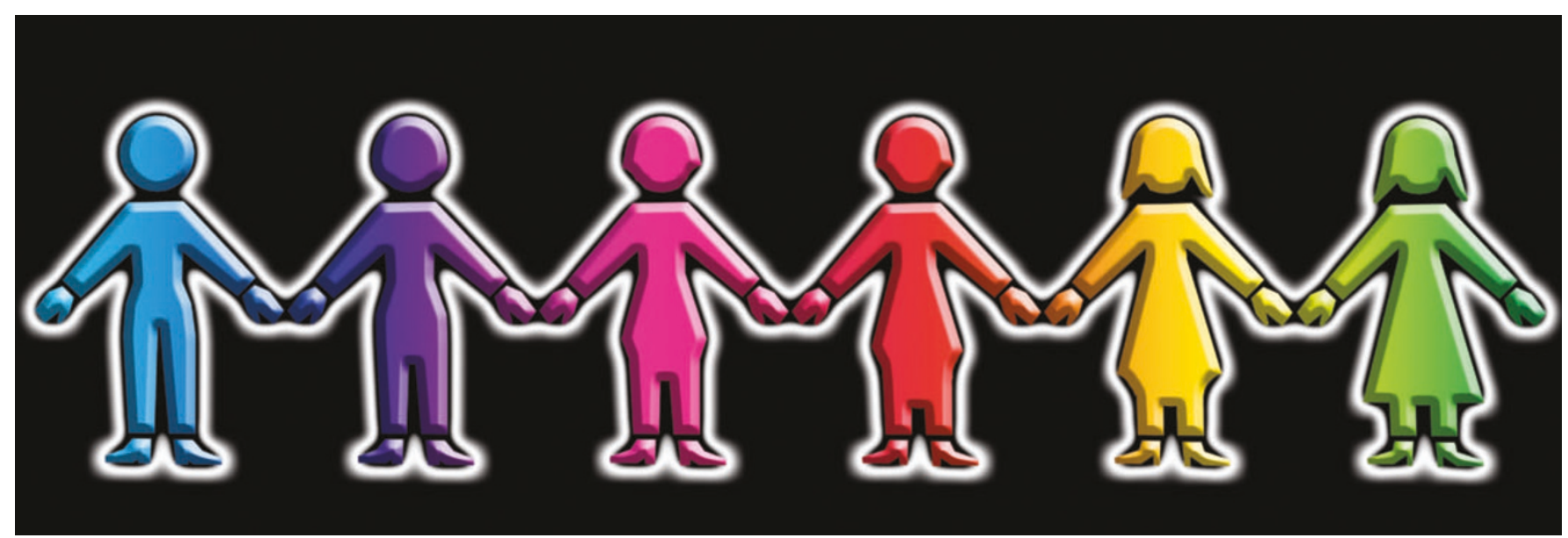

Catastrophes, published by the University of Chicago Press in 1997, show the advantages of identifying authors mentioned, giving full references for cited works, explaining allusions and discussing tricky points. But if the English prose here rarely sparkles, Geoffroy is largely to blame. On style, Cuvier won hands down.

So why should we read these works today? The Cuvier-Geoffroy debate has been given many different meanings, by the two sides at the time and by commentators since. For Le Guyader, molecular developmental biology allows us to recognize Geoffroy as a "visionary of genius" who-Le Guyader realizes it would be grossly anachronistic to call him right was "right to be wrong". A paper from 1822 certainly generates additional interest now that it is cited again. But the deeper reasons why Geoffroy still matters are the approaches that he and Cuvier framed and fought over, rather than any specific answers he gave. Their views decisively shaped our science. Nick Hopwood is in the Department of History and Philosophy of Science, University of Cambridge, Free School Lane, Cambridge CB2 $3 R H, U K$. He is the author of Embryos in Wax: Models from the Ziegler Studio.

\section{Sexual diversity and the gender agenda}

\section{Evolution's Rainbow: Diversity, Gender and Sexuality in Nature and People}

Joan Roughgarden

University of California Press: 2004. 472 pp. $\$ 27.50, £ 18.95$

\section{Sarah Blaffer Hrdy}

Rather than being one coherent book, the narrative of Evolution's Rainbow shuttles between three interwoven agendas. The first is a passionate cry from the heart for greater understanding of sexual diversity in nature and greater tolerance for the many gay men, lesbians, bisexuals, transgenders and others who do not fit comfortably into male or female binary categories.

The author, eminent Stanford biologist Joan Roughgarden, who is herself a transgendered woman previously known as John, cites poignant case studies that illustrate the anguish leading up to decisions to switch genders. As one such transgendered woman put it: "I've laid everything I've achieved in life — job, relationship, family, health, future - on the table, and it seems fate will decide what I am allowed to keep, if anything. It's kind of like starting life all over again." Roughgarden even includes rare practical advice on how to inform your boss that you intend to switch genders without losing your job. Few readers of Nature will disagree with the main tenets of what is essentially a human-rights agenda, even if they don't agree with all of Roughgarden's interpretations or policy recommendations.

The second, and for me most interesting, book-within-a-book provides a cornucopia of information about sex and gender diversity across human societies and the natural world. There are vignettes about homosexuals in Ancient Greece, eunuchs in Rome, hijras in India, and Native American 'two-spirits'. Roughgarden then takes us on a whirlwind tour through the zoological counterpart of human gender studies, introducing fish that change from females into males; intersex kangaroos that have a penis as well as a pouch equipped with mammary glands; kangaroo rats, in which up to $16 \%$ of a population have both sperm- and eggrelated plumbing; intersex bears that give birth through the penis; hermaphroditic whales; and homosexual black swans that turn out to be more successful at rearing young than their heterosexual counterparts.

For those familiar with the literature on sex differences, some of these gender-bending examples will be old hat, others quite new. A few sections are dazzlingly original, such as Roughgarden's imagined memoir of her own embryonic development. Wherever possible, she emphasizes the naturalness of gender gradations. She estimates that one in a thousand people are transgendered.
Iconoclastically, Roughgarden suggests that transsexuality is unlikely to be an anomaly: throughout the book, she is at pains to suggest ways in which gender ambiguity (such as feminine-seeming male fish) might be adaptive.

As a compendium of information on sex and gender diversity in the natural world, Roughgarden's is the richest and most authoritative book available, fulfilling a desperate need of readers both within and outside the scientific community. For readers craving information about transgendered existences, or for those like me who are deeply moved by Gay Pride parades and the social transformations that they represent, this book is going to have a huge impact. This is why I wish the third agenda had been more carefully considered.

In what Roughgarden herself views as the main message of the book, she lays out her reasons for rejecting Darwin's theory of sexual selection, as well as her grounds for an "indictment of academia for suppressing and denying diversity". The "facts of nature", she claims, falsify darwinian theory. She stresses instead that sex is essentially cooperative, is not a battle and often does not lead to conception. "We are only just realizing," she writes, "that the concepts of gender and sexuality we grew up with are seriously flawed." She argues that Darwin's theory of sexual selection is so flawed that it should be replaced by a theory of her own. However, I am less impressed by her critiques and alternative theory than by her timing. This evolutionary biologist becomes a woman, and only then do the problems occur to her?

It is a bad idea, argues Roughgarden, to move from a binary gender system based on gamete size (large eggs and small sperm) to explanations about differences in male and female body sizes, behaviours or mating strategies. It is ill advised, she says, to stereotype males as sexually ardent and females as coy; to ignore social or ecological constraints on female choice; to overemphasize genes at the expense of social or developmental contexts; or to give precedence to quests for supposedly the 'best' genes at the 